\title{
Crustal motion in E- and SE-Asia from GPS measurements
}

\author{
Gero W. Michel ${ }^{1}$, Matthias Becker ${ }^{2}$, Detlef Angermann ${ }^{1}$, Christoph Reigber ${ }^{1}$, and Ewald Reinhart ${ }^{2}$ \\ ${ }^{1}$ GeoForschungsZentrum Potsdam, Germany \\ ${ }^{2}$ Bundesamt für Kartographie und Geodäsie, Frankfurt am Main, Germany
}

(Received January 31, 2000; Revised June 1, 2000; Accepted June 2, 2000)

\begin{abstract}
Repeated GEODYSSEA-GPS measurements and additional GPS data from the IGS and APRGP97/98 constrain the motion of SE-Asia within a global reference frame. Sundaland i.e. Indochina as well as the western and central part of Indonesia, together with South-China, constitute an apparently stable tectonic block that is decoupled from Eurasia. In the ITRF97 this block moves to the east about an Euler pole approximating that of Eurasia, but with a velocity that is one third higher than the eastward directed movement of Eurasia. With respect to India and Australia the Sundaland-South China block is moving due south. This suggests that a) Sundaland-South China are moving coherently to the East along the boundaries studied and b) the eastward motion of India is compensated by the eastward motion of Sundaland-South China. The current rather homogeneous kinematic behaviour of SundalandSouth China that differs in rate (no more than $5 \mathrm{~mm}$ ) rather than direction from the movement of N-China differs from the kinematics proposed by different modelling approaches throughout the literature. The data help to constrain locations and behaviour of the active fault zones and give information on the interplate and intraplate deformation in the area.
\end{abstract}

\section{Introduction}

Differential motion of rigid plates and hence plate tectonics has enabled the description of the first order deformation characteristics of the oceanic lithosphere. To which extent the deformation of continents may be approximated by the motion of rigid plates or by distributed deformation and continuous flow, is the subject of controversial discussions.

Since the mid seventies, research in Central and SE-Asia focussed on the partitioning of deformation within and adjacent to the Himalayas/Tibet, the largest intracontinental orogenic ranges on earth. An accurate description and quantification of the mass that is currently transferred tectonically out of the collision zone north of the Indian indenter towards the subduction zones along the Pacific has been given a key role for understanding of intracontinental deformation (Thatcher, 1995 and references therein; Holt et al., 1995; England and Molnar, 1997). Further research topics in SE-Asia include: the distribution of stresses and strains within the collision zone between Australia and Eurasia (Puntodewo et al., 1994; Genrich et al., 1994; Walpersdorf et al., 1998a, b; Rangin et al., 1999), the complex deformation pattern that constitutes the Philippine Mobile Belt (Rangin et al., 1990; Duquesnoy et al., 1994; Rangin et al., 1999), the extent and distribution of seismic blocks in SE-Asia, and the related seismic loading and release behaviour (Prawirodirdjo et al., 1997; Michel et al., 1998; Zachariasen et al., 1999). Modern space geodesy has become a leading tool to study these topics, especially in areas such as SE-Asia where extensive cover of water and vegetation hinder large scale field investigations. In order to investigate the foregoing and other topics, repeated measure-

Copy right (C) The Society of Geomagnetism and Earth, Planetary and Space Sciences (SGEPSS); The Seismological Society of Japan; The Volcanological Society of Japan; The Geodetic Society of Japan; The Japanese Society for Planetary Sciences. ments were made of a GPS network extending over an area of 4000 by $4000 \mathrm{~km}$ (Fig. 1). The network has been measured in 1994, 1996, and 1998. The observations were conducted simultaneously at the 42 stations of the main network. Each station operated continuously over the entire period of every campaign. In addition to our own measurements we used GPS data from the Australian National Programme and data from the IGS and APRGP97/98 (Luton et al., 1998; AUSLIG, 1999, see also Becker et al., 2000).

The precision of the co-ordinate solutions was found to be $4-7 \mathrm{~mm}$ for the horizontal and $10 \mathrm{~mm}$ for the vertical components. The processing strategies, internal and external precision, apparent accuracy of data and results, and the strategies adopted for combining the solutions have been described in Becker et al. (2000) and Angermann (1998) and Angermann and Becker (2000).

\section{Seismic Deformation and Definition of Seismic Fault Blocks}

Measurements within the regional GEODYnamics of Sand SE-Asia (GEODYSSEA) GPS network do not aim at extensively mapping or monitoring transient effects related to the seismic loading cycle. GEODYSSEA relates to the behaviour of secular motion across SE-Asia. Abundant large earthquakes, however, suggest that transient seismic deformation processes may have influenced the observed GEODYSSEA site motions significantly (Michel et al., 1998; Rangin et al., 1999). Seismotectonic methods, together with dislocation modelling (Savage, 1983; Okada, 1985) have hence been applied to estimate the influence of seismic deformation on GEODYSSEA GPS site motions.

Teleseismic data of crustal earthquakes of the last 22 years (Harvard CMT solutions, Dziewonski et al., 1981) and data from the literature describing the traces of faults and the dis- 


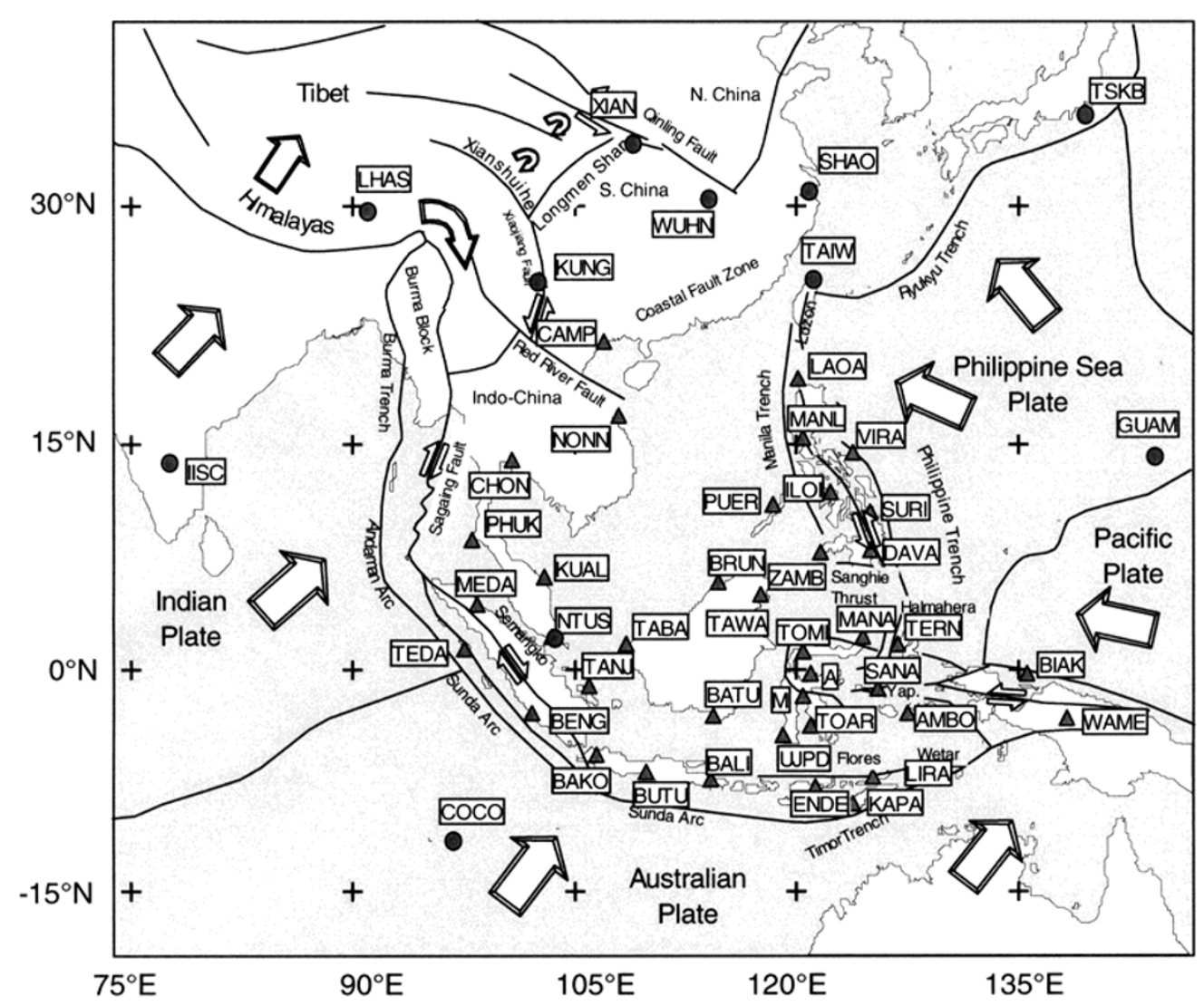

Fig. 1. Study area, GEODYSSEA GPS Network (triangles) and additional sites from IGS and APSGP (dots). A: AMPA, M: MALI.

tribution of fault segments or blocks (see e.g., Tjia, 1978; Newcomb and McCann, 1987) were used to a) map active faults, b) estimate their approximate traces, and c) describe their kinematic behaviour. Average plunges from the fault plane solutions served as the average dip of the fault segments considered. The lower edge of the seismogenic interface was approximated by the average depth of the hypocentres plus their 1 sigma error. The upper edge of the seismogenic interface was set at $10 \mathrm{~km}$. Relative NUVEL1A and/or GEODYSSEA motions revealed convergence directions and rates. Cumulative slip-directions were used to describe the kinematics of single fault blocks. Oblique convergence directions were partitioned according to the kinematic characteristics of the adjacent major faults (McCaffrey, 1996 and references therein).

Three dimensional dislocation modelling (Okada, 1985) was used a) to estimate the coseismic influence on the GEODYSSEA site motions of those earthquakes with moments larger than $2.5 \times 10^{18} \mathrm{Nm}$ that occurred between the campaigns and $b$ ) to approximate the surface deformation related to the elastic strain accumulation along fault segments (referred to elsewhere as back slip approaches). Except for the northern part of the Philippine Fault (Duquesnoy et al., 1994) and the roughly N-S trending plate boundary on Taiwan (Yu and Liu, 1989), all fault blocks were modelled as fully seismically coupled units. Later, it will be shown, that GEODYSSEA site motions help to verify this assumption along certain fault segments, whereas the assumption is re- jected along others. Due to the loosely defined rheology of the lower crust and upper mantle, no attempt was made at this stage to try to correct site motions using postseismic relaxation processes (e.g. Pollitz and Dixon, 1998).

Errors involved in the dislocation modelling originate from uncertainties in a) the considered rigidity, b) the teleseismically derived earthquake locations, c) the applied scaling laws (Scholz and Aviles, 1986; Wells and Coppersmith, 1994), and d) the uncertainties in the fault traces that are considered to be only loosely defined and easy to model approximations. Test-runs with end-member boundary conditions (epicentre location, segments sizes etc.) revealed uncertainties occasionally higher than $50 \%$ for the transient site effects including both coseismic strain release and interseismic elastic loading. Errors in the estimated slip-directions are considered to be of the order of the uncertainties of the geodetic measurements, i.e. approximately $10 \%$.

\section{Results}

\subsection{The seismic part of the GEODYSSEA site motions:} "seismic correction"

Figure 2 depicts focal mechanisms (CMT HarvardCatalogue; Dziewonski et al., 1981) of those large earthquakes with moments equal to or larger than $2.5 \times 10^{18} \mathrm{Nm}$ that occurred between the campaigns. Vectors indicate modelled coseismic and interseismic deformation. Results suggest that seismic deformation is restricted to the perimeters of the study area. 


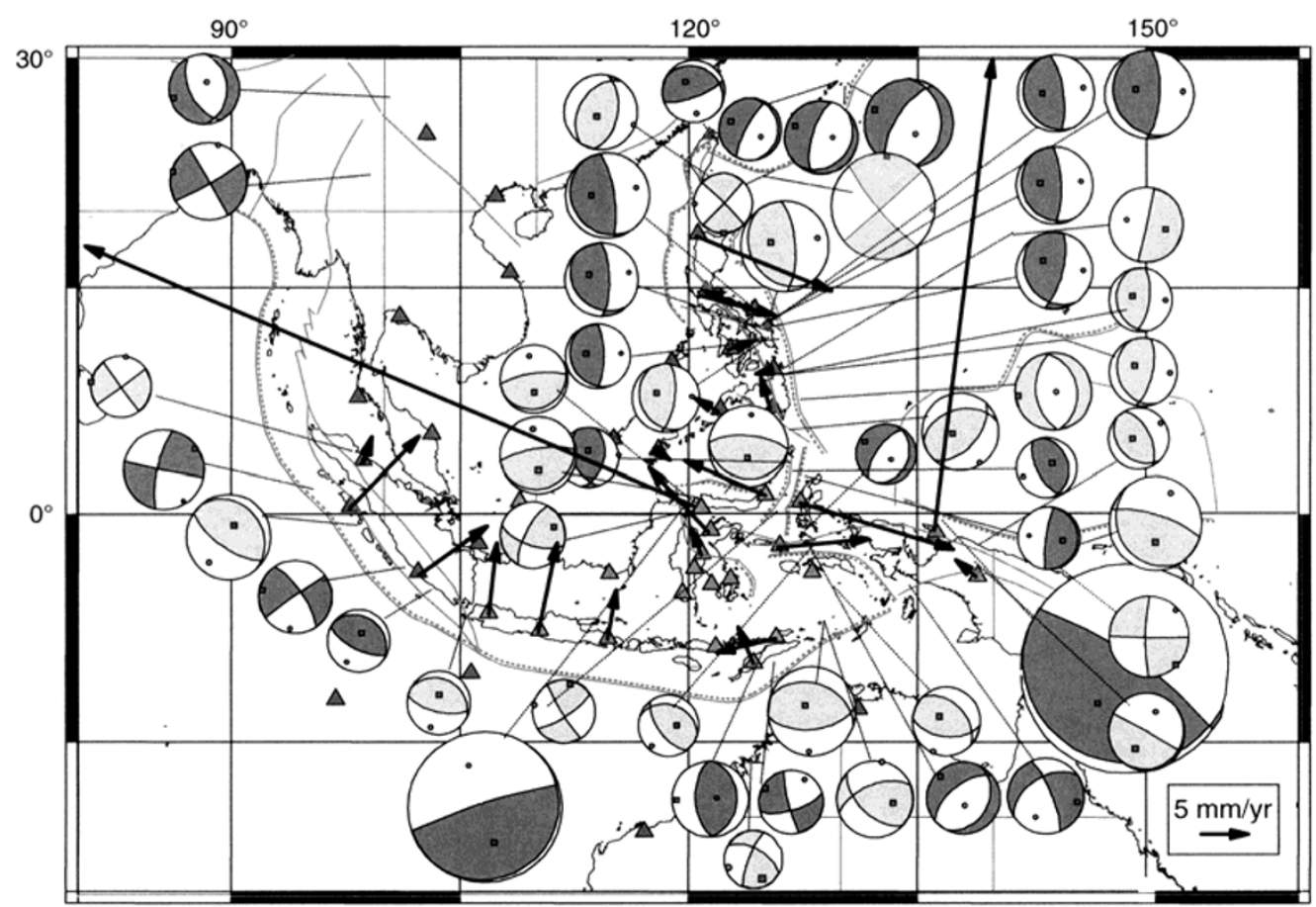

Fig. 2. GEODYSSEA stations (triangles) and focal mechanisms (CMT Harvard-Catalogue; Dziewonski et al., 1981) of those large earthquakes with moments equal to or larger than $2.5 \times 10^{18} \mathrm{Nm}$ that occurred between campaigns (dark grey: mechanism solutions of earthquakes that occurred between 1994-1996 campaigns, light grey: mechanism solutions of earthquakes between the 1996 and 1998 campaigns). Vectors indicate modelled coseismic and interseismic (full seismic coupling) deformation.

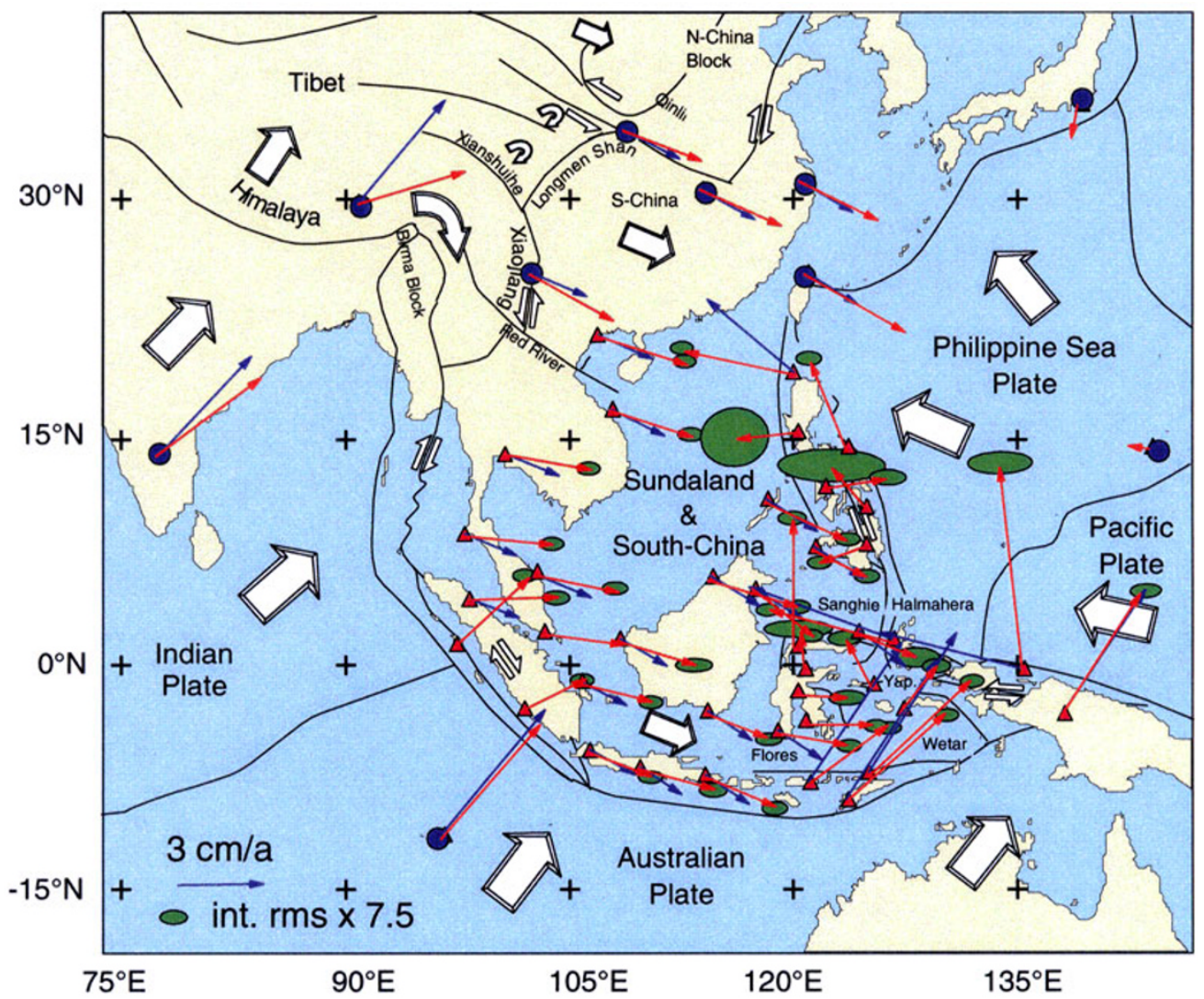

Fig. 3. Yearly site motions of GEODYSSEA sites and additional site motions of sites of the IGS and APSGP based on ITRF97. Site motions were derived using data measured in 1994, 1996, 1997, and 1998 (black arrows). Grey arrows represent the NNR-NUVEL1A solutions for the area. Error ellipses of the GEODYSSEA solution (see Becker et al., 2000) are multiplied by a factor of 7.5 in order to approximate the external error. 


\subsection{The Sundaland block and other plate and fault mod- els, and constraints for interpreting interseismic strain accumulation along individual fault blocks}

Models were considered to test the assumption that most of the fault segments depict full seismogenic coupling. Figure 3 shows yearly site motions based on ITRF97 (International Terrestrial Reference Frame, Boucher et al., 1999, see Becker et al., 2000). These were derived using data measured in 1994, 1996, 1997, and 1998. Using similar assumptions as the NNR-NUVEL1A model (DeMets et al., 1990, 1994), the geodetically derived ITRF solutions correlate well with those of the NNR-NUVEL1A model for those areas that are located within known stable plate interiors (Larson et al., 1997). Apparently this is not the case for SE-Asia where, according to the NNR-NUVEL1A model, Sundaland, S-China and N-China are rigidly attached to Eurasia. Except for the south-western most site on the Cocos island and the southeastern most site at Wamena (WAME), in Irian Jaya (Fig. 1), all GEODYSSEA site motions shown in Fig. 3 differ significantly from the NNR-NUVEL1A motions (Wilson et al., 1998a, b). Whereas the directions of GEODYSSEA site motions on the Sunda Shelf, Indochina, S-China, and the western and central parts of Indonesia approximate the directions of NNR-NUVEL1A motions, the rates are significantly different. In contrast to the active margins at the perimeters of the study area (Fig. 1), this area is relatively unaffected by recent seismicity (Wilson et al., 1998a, b) and apparently constitutes an almost stable Sundaland-South China (SSC) block. Figure 4 shows the residuals of stations that have been related to the SSC block. The Euler vector for this block was derived using the measured i.e. seismically uncorrected data of 15 core stations in a least squares adjustment algorithm (Fig. 4). The vector was located at $59.74 \pm 2.86^{\circ} \mathrm{N}$ and $-102.69 \pm 3.93^{\circ} \mathrm{E}$ and a rotation rate of $0.34 \pm 0.01^{\circ} / \mathrm{Myr}$ was derived. The core stations are assumed to reflect that part of the block that is not affected by interplate deformation along bounding faults. A comparison of the velocities of these stations with the velocities derived using the above Euler vector indicates that residuals are small, and in the order of the internal precision of the network solutions (Fig. 4).

Assuming that this SSC block does not show significant internal deformation, we used the modelled velocities to constrain the transient deformation along the seismically active margins. Arrows in Fig. 4 represent changes in the residuals for stations that are located in the vicinity of the block margins taking (tip of arrow) or not taking (arrow base) seismic correction into consideration. Most of the site motions fit the motion of the block slightly better with seismic correction than without. This is however not true for the sites on Java (BAKO, BALI, and BUTU), that fall well within the bounds of the estimated error ellipse before seismic correction, but exceed these limits by a considerable margin with correction. No large earthquake occurred there between campaigns and "seismic correction" is restricted to interseismic elastic loading. If the interface model used to describe loading at the Java margin is correct, this suggest that this part of the Sunda arc is not or only slightly effected by interplate elastic loading.

The stations TEDA and BENG are located SW of the active Semangko Fault (Fig. 1) and along the south-west border of the SSC block. After subtracting that part of the motion

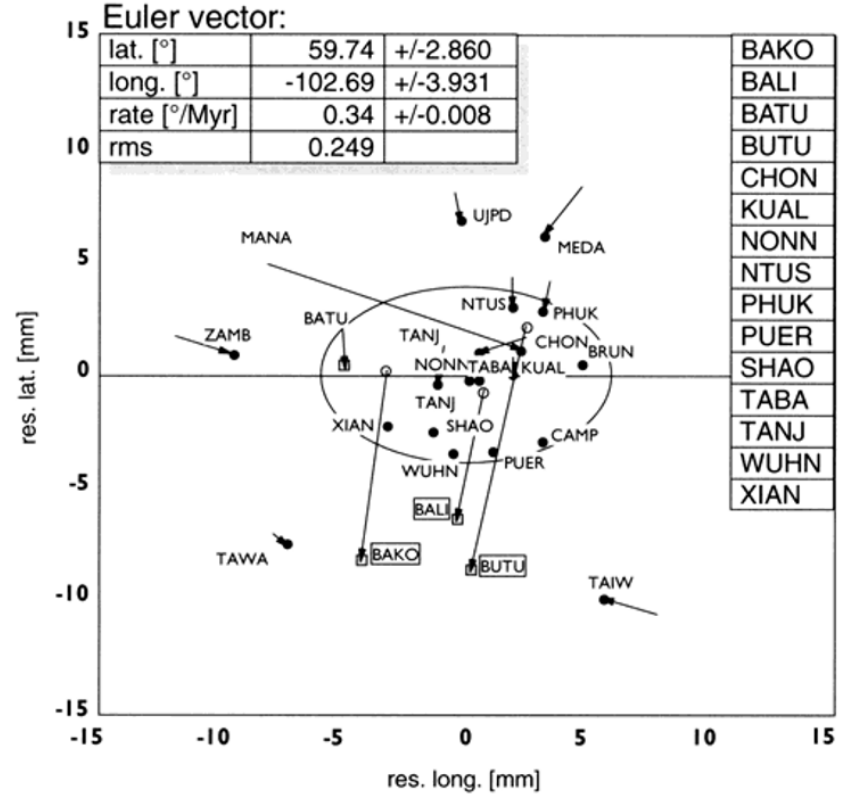

Fig. 4. Residuals to the SSC-modelled solution of sites at or adjacent to the SSC-Block as defined in the text (yearly motions). List at the right of the figure denotes stations that were assumed to lie on the stable SSC-Block. Measured ("seismically uncorrected") motions of these sites were used to compute the Euler vector as indicated in the upper left of the figure. Arrows depict changes in the residuals for those stations that are located in the vicinity of the block margins taking (tip of arrow) or not taking (arrow base) seismic correction into consideration. The sites BAKO, BALI, and BUTU fall well within the bounds of the estimated error ellipse without seismic correction, but exceed these limits with correction.

that is parallel to the Semangko Fault (26 and $20 \mathrm{~mm} / \mathrm{yr}$, TEDA, and BENG, respectively) residuals to the SSC-block constitute 20 (TEDA) and 12 (BENG) $\mathrm{mm} / \mathrm{yr}$. With residuals after seismic correction of 8 (TEDA) and 2 (BENG) $\mathrm{mm} / \mathrm{yr}$ these are to a large extent compensated when considering full seismic coupling along the active interplate margin. After seismic correction of the site motion of MANA (Fig. 1) in the vicinity of the Sanghie Trench, its residuals to the SSC block solution reach a fraction $(1 \mathrm{~mm} / \mathrm{yr})$ of the values before correction $(10 \mathrm{~mm} / \mathrm{yr})$. Significant changes in site motions for the two different time spans considered (19941996/1996-1998) for the station SURI on the Philippines correlate with the high seismicity along the Philippine trench. The only GEODYSSEA station located at the New Guinea trench (BIAK, Fig. 1) was shifted roughly $1 \mathrm{~m} \mathrm{~N}$ to NNE by a major, Ms: 8 earthquake in February 1996 (Stevens et al., 1996; Wilson et al., 1998a, b; Michel et al., 1998; Okal, 1999). The 1996-1998 solution for motion of this site also differs from the apparent long-term behaviour described by Puntodewo et al. (1994). It is suggested that this site is highly influenced by post-seismic relaxation processes.

Results of the above modelling suggest that: a) the Sunda arc depicts full seismic coupling in its NW whereas deformation is apparently more localised in the E, and b) the seismogenic interface along the Sanghie megathrust (Fig. 1) is largely coupled.

\subsection{Secular motions from the GEODYSSEA solution}

3.3.1 Strain rates In the following discussion, secular motion is referred to as that part of the yearly site motions that 


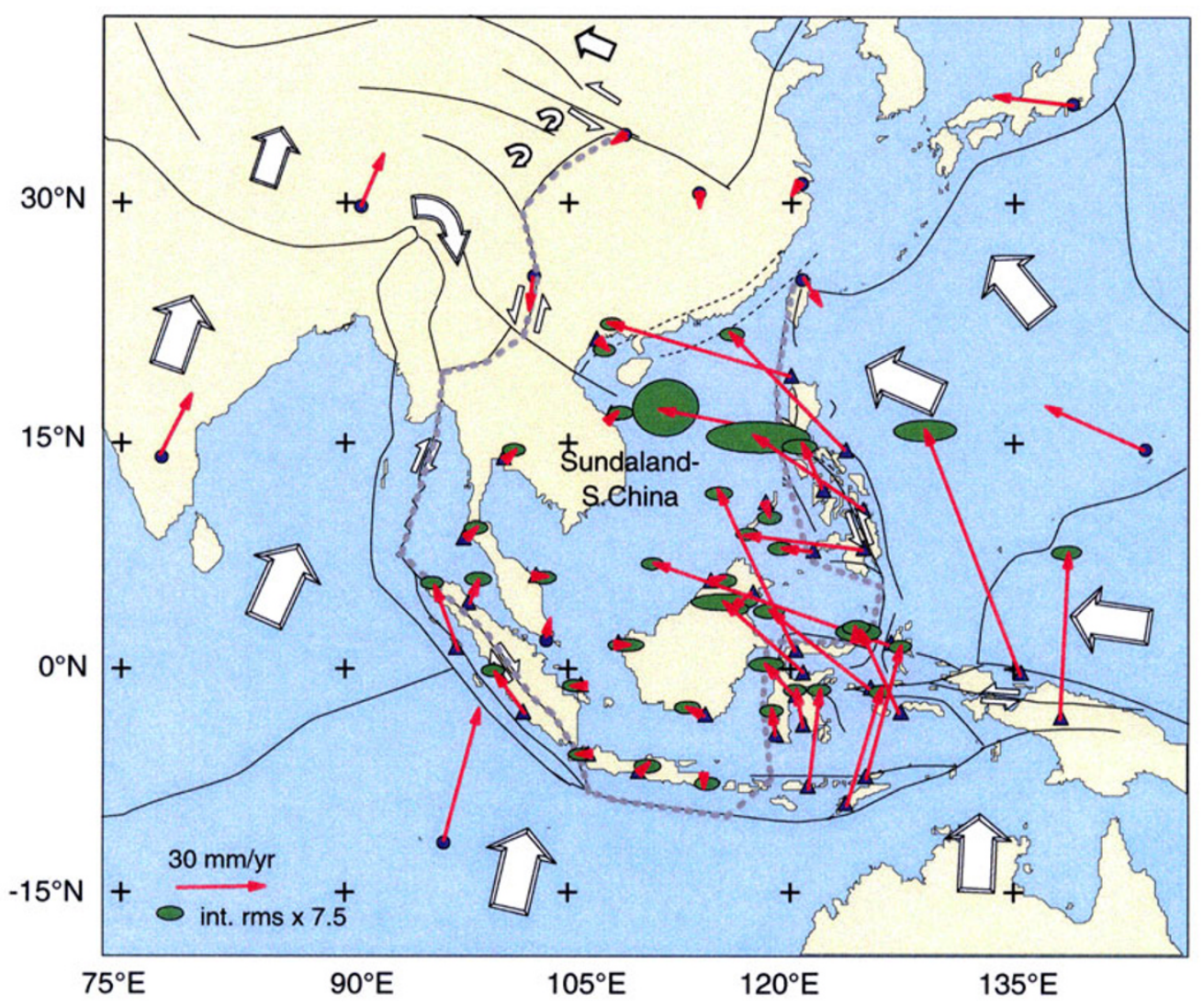

Fig. 5. Residual site motions with respect to SSC. As opposed to motions of sites on Java, site motions on Sumatra were "seismically corrected" according to assumptions explained in the text.

remains after applying results from seismic correction. Taking into account that GEODYSSEA stations constitute an average spacing of $500 \mathrm{~km}$ and co-ordinates have only been resolved to an average internal error of $5 \mathrm{~mm} / \mathrm{yr}$, it is reasonable to set the estimated lower threshold for interpretable strain rates at $1 \times 10^{-8} / \mathrm{yr}$. If considering the differential motion of sites at inter-station distances greater than the average 500 $\mathrm{km}$, this may be an underestimate of the precision of the solution. After seismic correction (site velocities on Java were not corrected as discussed above) the stations BALI, BAKO, BATU, BUTU, CHON, CAMP, KUAL, MANA, NONN, NTUS, PHUK, PUER, SHAO, TABA, TANJ, WUHN, XIAN define one major rigid i.e. undeformed block (Figs. 3, 5).

With an inter-station site distance of $690 \mathrm{~km}$, the differential strike slip motion along the Semangko Fault at sites TEDA with respect to BENG of 26 and $21 \pm 4 \mathrm{~mm} / \mathrm{yr}$ does suggest a tendency of higher slip rates along the western fault segments. This coincides with findings from others (McCaffrey, 1991).

Rates of site motions of the stations BALI, ENDE, KAPA and LIRA (Figs. 1, 3, 5), south of the Flores-Wetar back arc fault system increase continuously from $\mathrm{W}$ to $\mathrm{E}$. This is in agreement with high activity along the eastern back arc fault system (Genrich et al., 1994). Differential velocities along the fault system reach values of $6.8 \times 10^{-8} / \mathrm{yr}$ (KAPA/LIRA).

3.3.2 The Red River Fault Differential motion between the stations NONN and CAMP (Figs. 1, 3) north and south of the southern part of the Red River Fault, which is considered as the boundary between Indochina and S-China, is insignificant. Current rates along the fault are in the order of or lower than the $5 \mathrm{~mm} / \mathrm{yr}$ proposed by Allen et al. (1994) and Wang et al. (1998) using geological data. This corroborates differential motions from GPS measurements in eastern Tibet (King et al., 1997; Wang et al., 1998) but contradicts assumptions by others (Zhao, 1995; Peltzer and Saucier, 1996). Results from recent measurements in a local GPS network along the southern part of the Red River Fault suggest similar, low motion (if any) along this part of the fault (To et al., 1999). Taking the GPS data and the field evidence (Wang et al., 1998), stating that the Red River Fault has been displaced by the Xiaojiang Fault, it can be concluded that with respect to its present kinematics, the eastern part of the Red River Fault does not accommodate large motions nowadays.

\subsubsection{Differential motion between India and SSC}

The NNR-NUVEL1A solution for India was used as a reference for studying its kinematic behaviour with respect to $\mathrm{SSC}$. With respect to the latter, India is moving due $\mathrm{N}$ with a slight E component and a rate of $49 \pm 3 \mathrm{~mm} / \mathrm{yr}$ (Fig. 5). This motion is accommodated by: a) strike slip motion along the roughly N-S trending Sagaing or related faults $(48 \pm 2$ $\mathrm{mm} / \mathrm{yr}$ ) and oblique shortening with an E-W convergence of $10 \pm 4 \mathrm{~mm} / \mathrm{yr}$ along the Andaman and Burma trenches (see Rao and Kumar, 1999 and references therein, for discussion); b) N-S shortening within the Himalayan and Tibet ranges and c) rotation about the eastern syntaxis of India, and d) opening 
of the Andaman Sea. Motion of Lhasa (LHAS) with respect to "rigid" India (NUVEL1A) suggests that $23 \pm 3 \mathrm{~mm} / \mathrm{yr}$ of $\mathrm{N}-\mathrm{S}$ shortening is accommodated across the Nepal-Himalaya and adjacent areas. Westward directed motion of Lhasa with respect to India of $5 \pm 4 \mathrm{~mm} / \mathrm{yr}$ suggests that portions of south-eastern Tibet displace eastward (Larson et al., 1999). As $18 \pm 2 \mathrm{~mm} / \mathrm{yr}$ (Larson et al., 1999) of roughly N-S shortening is accommodated along the Himalayan thrust system, the rest i.e. $5 \pm 3 \mathrm{~mm} / \mathrm{yr}$ is apparently accommodated by additional N-S shortening across southern Tibet and/or EW extension. Kunming (KUNG), is moving due south with respect to SSC indicating sinistral movement along the $\mathrm{Xi}$ aojiang Fault system with a rate of $11 \pm 4 \mathrm{~mm} / \mathrm{yr}$. Geological data suggest that Kunming is located in an area were 3/4 of the overall relative motion rate of the Xiaojiang Fault system with respect to S-China has already been accommodated to the east of it (Wang et al., 1998). This suggests that the area west of the Xiaojiang Fault and Kunming and east of the eastern syntaxis of India moves southward with a rate of approximately $15 \mathrm{~mm} / \mathrm{yr}$ with respect to SSC (see King et al., 1997, for comparison). This confirms that a major part of the differential motion between Lhasa and Kunming is accommodated by rotation about the eastern syntaxis of India (King et al., 1997; Ratschbacher et al., 1996).

A major part of the relative movement between India and SE-Asia is hence accommodated by dextral motion along the Sagaing Fault or related fault systems. Northward directed motion is then transferred into clockwise rotation of material around the eastern syntaxis of India. Further measurements in more detailed networks are necessary to clearly explain this mechanism. The Xianshuihe-Xianjiang Fault system suffers pure sinistral strike slip faulting in its central part with respect to S-China without any resolvable convergent movement between Tibet and SSC. This also appears to be true for the boundary between Tibet and S-China to the north, where the Longmen Shan (Fig. 1) currently exhibits no shortening (King et al., 1997).

3.3.4 The Qinling Fault, motion with respect to the Amurian Plate Using permanent GPS stations north of the Qinling Fault system, Heki et al. (1999) computed that eastern N-China i.e. the area east of the Ordos block (Fig. 3, see Heki et al., 1999) is moving faster to the East than the Eurasian plate by a rate of 9-10 mm/yr (NNR-NUVEL1A solution). Using data from permanent stations, the precision of the estimation of Heki et al. (1999) is higher than that of the GEODYSSEA solutions and ranges in the order of 1-2 $\mathrm{mm} / \mathrm{yr}$. According to the GEODYSSEA solution, SSC is moving at a rate of $13 \pm 5 \mathrm{~mm} / \mathrm{yr}$ due east in a similar reference frame. Comparing Heki et al.'s solution for the kinematic behaviour of eastern N-China with the GEODYSSEA solution for SSC, it seems reasonable to suggest that current slip rates along the eastern part of the Qinling Fault are not higher than $5 \mathrm{~mm} / \mathrm{yr}$.

3.3.5 Coincidence between GEODYSSEA convergence directions and earthquake slip vectors along the Java trench Differential motion of Australia with respect to SSC is due North along the Java trench and suggests that the eastward directed movement is similar for both plates along the boundaries studied (Fig. 2). This coincides with seismic slip vectors that suggest that interplate motion is due
North along the Java trench. The apparent discrepancy between convergence direction and slip directions discussed in the literature (McCaffrey, 1991) thus appears to have been resolved. Convergence rates between Australia and SSC reach values of between 66 and $71 \pm 5 \mathrm{~mm} / \mathrm{yr}$.

3.3.6 Partitioning of convergent motion in the Banda region The behaviour of the sites BALI, ENDE, KAPA, and LIRA, north of the Timor trench indicate a significant $\mathrm{W}$ to $\mathrm{E}$ increase in the motion component parallel to the direction of interplate motion. A fully seismically coupled south verging plate interface along the Timor trench would account for only a fraction of the measured motion of ENDE, KAPA, and LIRA with remaining residuals of $35,52,55 \mathrm{~mm} / \mathrm{yr}$. Considering the high seismicity of the back arc thrust system, this suggests that motion is increasingly taken up, from $\mathrm{W}$ to E, there (Genrich et al., 1994 and references therein). Additionally, significant north-directed motion of the sites at UJPD, TOAR, AMBO, and SANA with respect to SSC suggest that some part of the motion is transferred far to the North and accommodated within the plate interior and/or the transition zone between Sundaland and Australia.

\subsubsection{Kinematic behaviour of SSC from} GEODYSSEA solutions and its relation to existing models As discussed above, the GEODYSSEA solution implies that SSC is moving due East in the ITRF97 reference frame with a rate that is one third higher than that of Eurasia. The differences between the previously published GEODYSSEA solution (Simons et al., 1999) (a) and the new solution (b) result from the improved ITRF reference frame used for the later solutions, the longer time span studied, and the higher availability of data from permanent sites. The major change lies in the decrease in velocities from north to south that has been suggested by solution a), taking into account that the external accuracy had not been treated adequately in the earlier interpretations (Angermann, 1998). Due to the new and more reliable solution, differential motion along the coastal fault zones on mainland China west of Taiwan do not have a significant influence on the GEODYSSEA site motions. With no resolvable motion along the eastern Red River Fault, this results in a huge apparently stable block that extends from the Sunda arc in the South to N-China in the North, from bivergent subduction in the Philippine mobile belt in the east (Cardwell et al., 1980; Rangin et al., 1990) to the Sagaing Fault and Burma/Andaman trenches in the south-west, and Tibet in the West and Northwest. At least the part of N-China studied by Heki et al. (1999), Kato et al. (1998), and Shen et al. (2000) shows a small amount of differential motion with respect to SSC. These results suggest that E- and SE-Asia exhibit different kinematic behaviour from that proposed by modelling (see Thatcher, 1995 and references therein; Peltzer and Saucier, 1996; England and Molnar, 1997, among others). Whatever might explain the behaviour of E- and SEAsia, the results presented here exclude rates of extrusionrelated motion and thickening that are significantly higher than $1: 4$ (Houseman and England, 1993), assuming that the NUVEL1A convergence rate between India and Eurasia is correct. 


\section{Discussion and Conclusion}

The results from three rounds of GPS measurements reveal new characteristics of current movements in E- and SE-Asia. In addition, further implications are tabled for the kinematics and seismic loading processes of individual faults and fault blocks. Among these are results that suggest that the Sunda arc depicts full seismic coupling in its NW whereas deformation is apparently more localised along its eastern part. Results further suggest that the motions across Sundaland and S-China are similar, within the confidence limits considered. The eastern Red River Fault, that is considered as the boundary between Sundaland and S-China, shows little, if any current activity. In the ITRF97 reference frame, motions of sites on SSC are coherently due east about an Euler pole roughly approximating that of Eurasia but with a velocity that is one third higher than the eastward directed movement of Eurasia. With respect to India, this SSC block is hence moving due South; a small amount of convergence between India and SSC is accommodated along the Andaman and Burma arc system. This implies that the eastwards motion of India is to a large extent compensated by the eastward directed motion of SE-Asia. This is still the case if we assume that the NUVEL1A convergence direction between India and Eurasia is approximately right whereas the velocity is an overestimate of about $4 \mathrm{~mm} / \mathrm{yr}$ of the actual velocity (Freymueller et al., 1996; Larson et al., 1999). A lower velocity of India with respect to Eurasia however results in a lower rate of differential dextral motion between India and SSC along the Sagaing and related faults.

Assuming that both E- and SE-Asia are pushed to the east by material flow out of Tibet, the rather homogeneous behaviour of the area suggests that this flow must be distributed rather homogeneously over a major part of eastern Tibet. Taking into account that the area constituted a jigsaw puzzle of blocks in the Tertiary (Hall, 1996), it behaves rather similarly nowadays. This apparent change from inconsistent to consistent behaviour may reflect a general change in the boundary conditions of E- and SE-Asia. This may be related to changes in shear traction induced by the onset of subduction along the Philippine trench in the late Miocene (Rangin et al., 1990; Hall, 1996) and/or could be related to the initiation of an increased eastward movement of India at $10 \mathrm{Ma}$ (Wiens et al., 1986; Chamot-Rooke et al., 1993).

We finally conclude that the GEODYSSEA results do not clearly favour either of the two end-member modelling approaches for intraplate deformation in Central Asia, i.e. those advocating continuum mechanics or expulsion of rigid blocks or platelets. However the findings clearly reject any model that includes current displacement of distinct rigid platelets that are differentially pushed out of Tibet towards SE-Asia due to $\mathrm{N}-\mathrm{S}$ shortening.

Acknowledgments. We thank Peter Wilson who initiated and coordinated the project during the years the project had been funded by the EU, for his never ending enthusiasm, ideas, and discussions. He helped fruitfully to develop this contribution. Several individuals have contributed to the project, too many to be mentioned hereinafter. Names can be found in a special GEODYSSEA issue available from the authors. We are grateful to Lothar Ratschbacher for his helpful comments and discussions. Comments by K. Heki and P. Morgan helped to improve the manuscript. Part of the project was carried out under Contract No. CI1*CT93-0337 between the European Commission and several agencies and institutions that are mentioned elsewhere in detail (Wilson et al., 1998a). The 1998 measurements were conducted and financed by the Bundesamt für Kartographie und Geodäsie (BKG), the GeoForschungsZentrum Potsdam (GFZ), and the local partners without supplementary financing. Thanks and appreciation is extended to the EC/EU and the ASEAN for their strong support and to the Australian Surveys and Land Information Group (AUSLIG), Canberra, Australia and the APSGP for providing additional data.

\section{References}

Allen, C. R., A. R. Gillespie, Y. Han, K. E. Sieh, B. Zhang, and C. Zhu, Red River and associated faults. Yunnan Province China: Quaternary geology, slip rates, and seismic hazard, Geol. Soc. Am. Bull., 95, 686$700,1984$.

Angermann, D., The datum definition of the GEODYSSEA network, in The Geodynamics of $S$ and SE Asia (GEODYSSEA) Project, edited by P. Wilson and G. W. Michel, Scientific Technical Report STR 98/14, pp. 113-119, Potsdam, 1998.

Angermann, D. and M. Becker, Untersuchungen zu Genauigkeit und systematischen Effekten in großräumigen GPS-Netzen am Beispiel von GEODYSSEA, ZfV, 3, 88-90, 2000

AUSLIG, http : / /www . permcom. auslig.gov . au, Canberra, 1999.

Becker, M., E. Reinhart, S. B. Nordin, D. Angermann, G. Michel, and C. Reigber, Improving the velocity field in South and South-East Asia: The third round of GEODYSSEA, Earth Planets Space, 52, this issue, 721-726, 2000.

Boucher, C., Z. Altamini, and P. Sillard, The 1997 International Terrestrial Reference Frame (ITRF97), IERS technical note 27, Observatoire de Paris, 1999.

Cardwell, R. K., B. L. Isacks, and D. E. Karig, The spatial distribution of earthquakes, focal mechanism solutions and subducted lithospheres in the Philippines and Northern Indonesian region, in The Tectonic and Geologic Evolution of Southeast Asian Seas and Islands, edited by D. E. Hayes, Geophys. Union. Monogr., 23, 1-35, 1980.

Chamot-Rooke, N., F. Jestin, B. De Voogd, and Phèdre working group, Intraplate shortening in the central Indian Ocean determined from a 2100$\mathrm{km}$-long north-south deep seismic reflection profile, Geology, 21, 10431046, 1993.

De Mets, C., R. G. Gordon, D. F. Argus, and S. Stein, Current plate motion, Geophys. Res. Lett., 101, 425-478, 1990.

De Mets, C., R. G. Gordon, D. F. Argus, and S. Stein, Effects of recent revisions to the geomagnetic reversal time scale on estimates of current plate motions, Geophys. Res. Lett., 21, 2191, 1994.

Duquesnoy, T., E. Barrier, M. Kasser, M. Aurelio, R. Gaulon, R. S. Punongbayan, C. Rangin, and the French-Philippine Cooperation Team, Crustal Strain along the North Cascadia Margin observed from continuous GPS monitoring, Geophys. Res. Lett., 21, 975-978, 1994.

Dziewonski, A. M., T.-A. Chou, and J. H. Woodhouse, Determination of earthquakes source parameters from waveform data for studies of global and regional seismicity, J. Geophys. Res., 86, 2825-2852, 1981.

England, P. and P. Molnar, The field of crustal velocity in Asia calculated from Quaternary rates of slip on faults, Geophys. J. Int., 130, 551-582, 1997.

Freymueller, J., R. Bilham, R. Burgmann, K. M. Larson, J. Paul, S. Jade, and V. Gaur, Global positioning system measurements of Indian plate motion and convergence across the Lesser Himalaya, Geophys. Res. Lett., 23, 3107-3110, 1996.

Genrich, J., Y. Bock, R. McCaffrey, E. Calais, C. Stevenson, et al., Kinematics of the eastern Indonesian island arc estimated by Global positioning system measurements, EOS, 75, 162, 1994.

Hall, R., Reconstructing Cenozoic SE Asia, in Tectonic Evolution of SE Asia, edited by R. Hall and D. J. Blundell, pp. 153-184, Geol. Soc. Spec. Pub., 106, 1996.

Heki, K., S. Miyazaki, H. Takahashi, M. Kasahara, F. Kimata, S. Miura, N. F. Vasilanko, A. Ivashchenko, and K.-D. An, The Amurian Plate motion and current plate kinematics in eastern Asia, J. Geophys. Res., 104, 2914729155, 1999.

Holt, W. E., M. Li, and A. J. Haines, Earthquake strain rates and instantaneous relative motions within central and eastern Asia, Geophys. J. Int. 122, 569-593, 1995.

Houseman, G. and P. England, Crustal thickening versus lateral expulsion in the India-Asian continental collision, J. Geophys. Res., 98, 12233-12249, 
1993.

Kato, T., Y. Kotake, S. Nakao, J. Beavan, K. Hirahara, M. Okada, M. Hoshiba, O. Kamigaichi, R. B. Feir, P. H. Park, M. D. Gerasimenko, and M. Kasahara, Initial results from WING, the continuous GPS network in the western Pacific area, Geophys. Res. Lett., 25, 369-372, 1998.

King, R. W., F. Shen, B. C. Burchfiel, E. Wang, Z. Chen, Y. Liu, X. Y. Zhang, J. X. Zhao, and Y. Li, Geodetic measurements of crustal motion in southwest China, Geology, 25, 179-182, 1997.

Larson, K. M., J. Freymueller, and S. Philipson, Global plate velocities from the Global Positioning System, J. Geophys. Res., 102, 9961-9982, 1997.

Larson, K. M., R. Bürgmann, R. Bilham, and J. Freymueller, Kinematics of the India-Eurasia collision zone from GPS measurements, J. Geophys. Res., 104, 1077-1093, 1999.

Luton, G., J. Dawson, R. Govind, and D. T. Sproule, APRGP97 Observation Campaign Overview, edited by AUSLIG, Proceedings of the Workshop on Regional Geodetic Network: 23-24, Canberra, Australia, July 2-4, 1998.

McCaffrey, P., Slip vectors and stretching of the Sumatran fore arc, Geology, 19, 881-884, 1991.

McCaffrey, R., Slip partitioning at convergent plate boundaries of SE Asia, in Tectonic Evolution of Southeast Asia, edited by R. Hall and D. J. Blundell, pp. 3-18, Geol. Soc. Spec. Pub., 106, 1996

Michel, G. W., D. Angermann, P. Wilson, Ch. Reigber, and J. Klotz, Transient versus secular motion: the possible impact of earthquakes and interseismic loading on the GEODYSSEA site motions, in The Geodynamics of $S$ and SE Asia (GEODYSSEA) Project, edited by P. Wilson and G. W. Michel, Scientific Technical Report STR 98/14, pp. 75-97, Potsdam, 1998

Newcomb, K. R. and W. R. McCann, Seismic history of the Sunda Arc, J. Geophys. Res., 92, 421-439, 1987.

Okada, Y., Surface deformation due to shear and tensile faults in a half-space, Bull. Seismol. Soc. Am., 75, 1135-1154, 1985.

Okal, E. A., Historical seismicity and seismotectonic context of the great 1979 Yapen and 1966 Biak, Irian Jaya earthquakes, Pure Appl. Geophys., 154, 633-675, 1999.

Peltzer, G. and F. Saucier, Present-day kinematics of Asia derived from geologic fault rates, J. Geophys. Res., 101, 27943-27956, 1996.

Pollitz, F. and T. H. Dixon, GPS measurements across the northern Carribbean plate boundary zone: Impact of postseismic relaxation following historic earthquakes, Geophys. Res. Lett., 25, 2233-2236, 1998.

Prawirodirdjo, L., Y. Bock, R. McCaffrey, J. Genrich, E. Calais, C. Stevens, S. S. Puntodewo, C. Subaraya, J. Rais, P. Zwick, and Fauzi, Geodetic observation of interseismic strain segmentation at the Sumatra subduction zone, Geophys. Res. Lett., 24, 2601-2604, 1997.

Puntodewo, S. S., R. McCaffrey, E. Calais, Y. Bock, J. Rais, C. Subaraya, R. Poewariardi, C. Stevens, J. Genrich, Fauzi, P. Zeick, and S. Wdowinski, GPS measurements of crustal deformation within the Pacific-Australia plate boundary zone in Irian Jaya, Indonesia, Tectonophys., 237, 141$153,1994$.

Rangin, C., L. Jolivet, M. Pubellier, and the Tethys Pacific Working Group, A simple model for the tectonic evolution of Southeast Asia and Indonesia region for the past 43 m.y., Bull. Soc. Géol. France, 8, 889-905, 1990.

Rangin, C., X. Le Pichon, S. Mazzotti, M. Pubellier, N. Chamot-Rooke, M Aurelio, A. Walpersdorf, and R. Quebral, Plate convergence measured by GPS across the Sundaland/Philippine Sea Plate deformation boundary: Philippines and eastern Indonesia, Geophys. J. Int., 139, 296-316, 1999.

Rao, N. P. and M. R. Kumar, Evidence for cessation of Indian plate subduction in the Burmese arc region, Geophys. Res. Lett., 26, 3149-3152, 1999.

Ratschbacher, L., W. Frisch, C. Chen, and G. Pan, Cenozoic deformation, rotation, and stress patterns in eastern Tibet and western Sichuan, China, in The Tectonic Evolution of Asia, edited by A. Yin und T. M. Harrison, pp. 227-249, The Tectonic evolution of Asia, 63-84, Cambridge University Press, 1996
Savage, J. C., A dislocation model of strain accumulation and release at a subduction zone, J. Geophys. Res., 88, 4988-4996, 1983.

Scholz, C. H. and C. Aviles, The fractal geometry of faults and faulting, in Earthquake Source Mechanisms, edited by S. Das, J. Boatwright, and C. Scholz, AGU Geophys. Monogr., 37., pp. 147-155, Scaling laws for large earthquakes: Consequences for physical models, Bull. Seismol. Soc. Am. 82, 1-14, 1986

Shen, Z., C. Zhao, Y. Li, D. D. Jackson, P. Fang, and D. Dong, Contemporary crustal deformation in east Asia constrained by Global Positioning System measurements, J. Geophys. Res., 105, 5721-5734, 2000.

Simons, W. J. F., B. A. C. Ambrosius, R. Noomen, D. Angermann, P. Wilson, M. Becker, E. Reinhart, A. Walpersdorf, and C. Vigny, Plate Motions in South East Asia: results of the GEODYSSEA Project, Geophys. Res. Lett., 26, 2081-2084, 1999.

Stevens, C., P. Zwick, R. McCaffrey, Masturyono, Fauzi, J. Nabelek, B. Schurr, Y. Bock, J. Genrich, S. S. O. Puntodewo, and C. Surabaya, The February 17, 1996, Mw=8.2 Biak earthquake: GPS measurements, Coseismic seal-level changes, and aftershocks, EOS Trans. AGU, 77, F520, 1996.

Thatcher, W., Microplate versus continuum descriptions of active tectonic deformation, J. Geophys. Res., 100, 3885-3895, 1995.

Tjia, H. D., Active faults in Indonesia, Geo. Soc. Malaysia, 10, 73-92, 1978

To, T. D., N. T. Yem, D. C. Cong, V. Q. Hai, M. Becker, E. Reinhart, and G. W. Michel, GPS measurements across the Red River Fault from 1994 to 1998, AGU Fall Meeting, G51-C13, 1999.

Walpersdorf, A., C. Vigny, C. Subaraya, and P. Manurung, Monitoring of the Palu-Koro Fault (Sulawesi) by GPS, Geophys. Res. Lett., 25, 2313-2316, 1998a.

Walpersdorf, A., C. Vigny, P. Manurung, C. Subaraya, and S. Sutisna, Determining the Sula block kinematics in the triple junction area in Indonesia by GPS, Geophys. J. Int., 135, 351-361, 1998b.

Wang, E., B. C. Burchfiel, L. H. Royden, C. Liangzhong, C. Jishen, L. Wenxin, and C. Zhiliang, Late Cenozoic Xianshuihe-xiaojiang, Red River, and Dali Fault Systems of Southwestern Sichuan and Central Yunnan, China, GSA Special Paper, 327, 108 pp., 1998.

Wells, D. L. and K. J. Coppersmith, New empirical relationships among magnitude, rupture length, rupture width, rupture area and surface displacement, Bull. Seismol. Soc. Am., 84, 974-1002, 1994.

Wiens, D. A., S. Stein, C. De Mets, R. G. Gordon, and C. Stein, Plate tectonic models for Indian Ocean "intraplate" deformation, Tectonophys. 132, 37-48, 1986.

Wilson, P., J. Rais, and The GEODYSSEA project: An investigation of the geology and geodynamics of South and Southeast Asia, in The Geodynamics of $S$ and SE Asia (GEODYSSEA) Project, edited by P. Wilson and G. W. Michel, Scientific Technical Report STR, 98/14, pp. 9-27, Potsdam, 1998a.

Wilson, P., J. Rais, Ch. Reigber, E. Reinhart, B. A. C. Ambrosius, X. Le Pichon, M. Kasser, P. Suharto, Dato' Abdul Majid, Dato' Paduka Awang Haji Othoman Bin Haji Yaakub, and E. Almeda, The GEODYSSEA project: An investigation of the geology and geodynamics of South and South-East Asia, EOS, 79, 545, 548-549, 1998b.

Yu, S. B. and C. C. Liu, Fault creep on the central segment of the Longitudinal Fault, eastern Taiwan, Proc. Geol. Soc. China, 32, 209-231, 1989.

Zachariasen, J., K. Sieh, F. W. Taylor, R. L. Edwards, and W. S. Hantoro, Submergence and uplift associated with the giant 1833 Sumatran subduction earthquake: Evidence from coral microatolls, J. Geophys. Res., 104, 895-919, 1999

Zhao, S., Joint inversion of observed gravity and GPS baseline changes for the detection of the active fault segment of the Red River fault zone, Geophys. J. Int., 122, 70-88, 1995.

G. W. Michel (e-mail: fault@gfz-potsdam.de), M. Becker, D. Angermann, C. Reigber, and E. Reinhart 